\begin{tabular}{|c|l|}
\hline Title & $\begin{array}{l}\text { A THEORETICAL ANALYSIS OF HABITAT CONVERSION AND BIODIVERSITY CONSERVATION OVER } \\
\text { TIME AND UNDER UNCERTAINTY }\end{array}$ \\
\hline Sub Title & \\
\hline Author & BATABYAL, Amitrajeet A. \\
\hline Publisher & Keio Economic Society, Keio University \\
\hline Publication year & 2002 \\
\hline Jtitle & Keio economic studies Vol.39, No.2 (2002. ),p.33- 44 \\
\hline JaLC DOI & \\
\hline Abstract & $\begin{array}{l}\text { We exploit the known links between natural habitats and biodiversity to pose and study the } \\
\text { biodiversity conservation question as an optimal stopping problem. We extend the extant } \\
\text { literature on this question by studying the role that autonomous and nonautonomous policies } \\
\text { play in the decision to conserve biodiversity over time and under uncertainty. We first construct a } \\
\text { dynamic and stochastic model of decision making in the context of biodiversity conservation. } \\
\text { Next, we use this model to analyze the expected utility of a social planner when this planner } \\
\text { uses, respectively, autonomous and nonautonomous policies. Finally, we compare and contrast } \\
\text { the properties of autonomous and nonautonomous conservation policies and we discuss the } \\
\text { magnitude of the flexibility premium stemming from the maintenance of temporal flexibility in } \\
\text { decision making. }\end{array}$ \\
\hline Notes & \begin{tabular}{l} 
Journal Article \\
\hline Genre
\end{tabular} \\
\hline URL & \begin{tabular}{l} 
https://koara.lib.keio.ac.jp/xoonips/modules/xoonips/detail.php?koara_id=AA00260492-2002000 \\
\hline
\end{tabular} \\
\hline
\end{tabular}

慶應義塾大学学術情報リポジトリ(KOARA)に掲載されているコンテンツの著作権は、それぞれの著作者、学会または出版社/発行者に帰属し、その権利は著作権法によって 保護されています。引用にあたっては、著作権法を遵守してご利用ください。

The copyrights of content available on the KeiO Associated Repository of Academic resources (KOARA) belong to the respective authors, academic societies, or publishers/issuers, and these rights are protected by the Japanese Copyright Act. When quoting the content, please follow the Japanese copyright act. 


\title{
A THEORETICAL ANALYSIS OF HABITAT CONVERSION AND BIODIVERSITY CONSERVATION OVER TIME AND UNDER UNCERTAINTY
}

\author{
Amitrajeet A. BATABYAL \\ Department of Economics, Rochester Institute of Technology, Rochester, USA
}

First version received October 2002; final version accepted October 2002

\begin{abstract}
We exploit the known links between natural habitats and biodiversity to pose and study the biodiversity conservation question as an optimal stopping problem. We extend the extant literature on this question by studying the role that autonomous and nonautonomous policies play in the decision to conserve biodiversity over time and under uncertainty. We first construct a dynamic and stochastic model of decision making in the context of biodiversity conservation. Next, we use this model to analyze the expected utility of a social planner when this planner uses, respectively, autonomous and nonautonomous policies. Finally, we compare and contrast the properties of autonomous and nonautonomous conservation policies and we discuss the magnitude of the flexibility premium stemming from the maintenance of temporal flexibility in decision making.
\end{abstract}

Key words: Flexibility premium, biodiversity conservation, natural habitat, optimal stopping.

JEL Classification Number: Q28, D81.

\section{INTRODUCTION}

A considerable amount of concern has been expressed in recent times about the decline in the world's diverse biological resources. Economists and ecologists now acknowledge that not only are we losing biological diversity (hereafter biodiversity), we are losing it at an unparalleled rate (Swanson, 1995a, p. xi). Casual explications for the problem of biodiversity loss abound. However, it is only very recently that economists and ecologists have begun to combine their resources to systematically analyze issues relating to the loss and the conservation of biodiversity. ${ }^{1}$ A salient conclusion emanating

Acknowledgement. We thank an anonymous referee and Makoto Yano for their helpful comments on a previous version of this paper. As well, we thank the Gosnell endowment at RIT for financial support. This paper is dedicated to the memory of A. N. Batabyal (1937-2002). The usual disclaimer applies. E-mail: aabgsh@rit.edu

1 For more on this joint research, see the papers in Perrings et al. (1995a) and Swanson (1995a).

Copyright (C) 2002, by the Keio Economic Society 
from this joint "ecological-economic" approach to the subject is that when considering the problem of biodiversity loss, it is generally inappropriate to focus on the loss of genetic information. Instead, what researchers should be concentrating on are the nexuses between biodiversity loss and the parallel loss of ecosystem resilience (Perrings et al., 1995b, pp. 16-17).

Beyond this general finding, economists and ecologists have analyzed three additional issues related to biodiversity. These issues concern the measurement of biodiversity, a determination of the causes for the decline in biodiversity, and the valuation of biodiversity. The measurement issue has been studied by Weitzman $(1992,1993,1995)$, Solow et al. (1993), and Solow and Polasky (1994). These scholars have shown that the genetic distance between related species can be used to devise an effective measure of biodiversity. This measure recognizes that the "optimal conservation policy may be defined as the feasible action that yields the highest discounted expected value of diversity (plus whatever other net benefits are attributed to various components)" (Weitzman, 1995 , p. 22). It is salient to comprehend that this measurement issue has been guided by the realization that conservation resources are scarce. Consequently, in order to ascertain how these scarce resources ought to be allocated across competing needs, it is necessary to measure biodiversity.

Studies of the causes for the decline in biodiversity have been conducted by Barbier and Rauscher (1995), Gadgil (1995), and Southgate (1995). ${ }^{2}$ By revealing a causal connection between myopic policy-making and a diminution in biodiversity, these researchers have pointed to the need for devising conservation policies that take into account the economics and the ecology of the biodiversity loss problem. Specifically, Gadgil (1995, p. 107) has pointed out that such policies must acknowledge that the problem of biodiversity loss is closely connected to "the ever-growing resource demands of [citizens of the First World and the Third World elite]. . . and their willingness to permit resource degradation in tracts outside their domain of concern."

Finally, the valuation of biodiversity has become a major issue not only because of the established connection between biodiversity loss and the loss of ecosystem resilience, but more narrowly, because of its close connection to "biodiversity prospecting," and therefore to the probable discovery of new pharmaceutical products. Polasky and Solow (1995), Simpson et al. (1996) and others have analyzed this valuation issue. These authors have shown that by deriving a demand curve for native genetic resources, one can ascertain the marginal willingness to pay for the marginal species and the marginal hectare of threatened habitat.

Although this body of research has certainly advanced our understanding of many facets of the biodiversity conservation question, it is still true that the extant literature has not analyzed the effects that alternate policies have on the decision to conserve biodiversity and on a social planner's expected utility from conservation. Consequently, our paper has three objectives. However, before we discuss the objectives themselves, it

2 Readers should also consult Swanson (1995a) and the papers in Perrings et al. (1995a). 
is necessary to first comment on the relationship between natural habitats and biodiversity. The essential point is this: The conversion of natural habitats invariably leads to a loss of biodiversity. For instance, Smith et al. (1995, p. 134) have remarked that overexploitation, the introduction of exotic species, and habitat conversion are "the three primary causes of. . . extinctions and endangerments. .."3

The problems associated with habitat conversion are grave. Consider the case of tropical forests, generally acknowledged to be an important source of biodiversity. As noted in Myers (1992, pp. 175-176), commercial logging, fuelwood gathering, cattle raising, and forest farming operations collectively result in the conversion of approximately 200,000 square kilometers of primary forest every year. This massive conversion of tropical forests has given rise to the following two disturbing statistics: First, the tropical forests of West Africa, the Greater Antilles, India, Madagascar, the Philippines, and Atlantic Brazil have already been reduced to less than 10 per cent of their original areas (Terborgh and van Schaik, 1997). Second, as pointed out in Terborgh (1992), outside of protected areas, tropical forests are expected to endure for only about 35 to 40 more years. Regrettably, despite the increased global attention to the loss of tropical forests, it does not appear as though the rate of forest conversion is slowing down. Recent studies by Whitmore and Sayer (1992) and by Aldhous (1993) suggest that this conversion rate is actually increasing in a number of nations.

With these sobering statistics in mind, let us now discuss the three objectives of this paper. First, we construct a dynamic and stochastic model of decision making in the context of biodiversity conservation. Next, we use our model to shed light on a question that, to the best of our knowledge, has not been studied previously in the literature on the conservation of biodiversity. This question concerns the expected utility of a social planner when this individual is able to choose between autonomous (time independent) and nonautonomous (time dependent) conservation policies. Finally, we compare and contrast the attributes of autonomous and nonautonomous policies and then we discuss the magnitude of the flexibility premium arising from the maintenance of temporal flexibility in decision making.

To see why the distinction between autonomous and nonautonomous policies is salient, note the following: Autonomous policies are rigid and they do not permit a social planner to alter his or her policy when new information is acquired. Put differently, new information about the consequences of habitat conversion cannot be incorporated into the policy. In contrast, nonautonomous policies are flexible and they permit the incorporation of new information about the effects of habitat conversion into the policy. Therefore, intuitively one expects to observe a flexibility premium associated with the use of a nonautonomous policy. Indeed, we explore the existence and the magnitude of this flexibility premium in section 4 of this paper.

3 For more on the relationship between habitat conversion and biodiversity loss, see Myers (1992), Wilson (1992), Ehrlich (1994), Hartwick (1995), and Krautkraemer (1995). In particular, Myers (1992, pp. 379-383) provides a country by country review of conversion rates in tropical forests. 
The theory of optimal stopping (see Ross (1983), Dixit and Pindyck (1994), and Batabyal $(1998,2000)$ ) can be used to shed light on the objectives of this paper. Consequently, our paper can also be thought of as an application of this theory to the problem of habitat conversion and biodiversity conservation over time and under uncertainty. The papers that are most closely related to our paper are Batabyal $(1998,2000)$. Both these papers study biodiversity conservation over time and under uncertainty. However, the objective of Batabyal (1998) is exclusively on characterizing the optimal time at which a habitat conversion process ought to be halted. In Batabyal (2000), the focus is on studying the link between a social planner s optimal conservation policy and the length of his or her planning horizon. Neither paper has analyzed the properties of autonomous and nonautonomous policies in the context of biodiversity conservation over time and under uncertainty.

The rest of this paper is organized as follows: Section 2 presents the theoretical framework. Section 3 uses this framework and provides a detailed analysis of the effects of autonomous and nonautonomous policies on the expected utility of a social planner contemplating the conservation of biodiversity. Section 4 discusses the properties of autonomous and nonautonomous conservation policies and then comments on the magnitude of the premium arising from the maintenance of temporal flexibility in decision making. Section 5 concludes and offers suggestions for future research on the subject of this paper.

\section{THE THEORETICAL FRAMEWORK}

In order to keep things from getting unduly complicated, in the rest of this paper we shall choose units so that the numerical values of all the pertinent variables and the distribution functions are drawn from the interval $(0,1]$. Now, consider a country such as Indonesia in which the conversion of natural habitat into developed land is taking place over time. ${ }^{4}$ As Wilson (1992) and Krautkraemer (1995) have pointed out, estimates of the rate of species loss are generally based on the rate of habitat loss. Therefore, we shall interpret the area of natural habitat as a measure of the stock of biodiversity. ${ }^{5}$ The conversion of natural habitat yields information about the consequences of development and the existing stock of biodiversity. This link between habitat conversion and information acquisition has been documented in the extant literature. For instance, Swanson (1995b, p. 247) has noted that sequential "decision making regarding... conversions

\footnotetext{
4 We have posed the decision making problem at the level of a country. However, a change of scale-to a region within a country or to a region encompassing more than one country - does not affect the analysis qualitatively.

5 This interpretation has been used previously in the literature. For more details, see Barrett (1995, p. 285). However, note that for some "hot spot" habitats (see Myers, 1992, pp. xxi-xxii), the use of the area of natural habitat as a measure of the stock of biodiversity will need to be augmented to account for the fact that these "hot spot" habitats contain species that are at risk and are found nowhere else. This augmentation can be accomplished by letting the social planner's utility function (see the next paragraph) depend on both the information packets and on a second variable that is an indicator of biodiversity quality.
} 
implies the passage of time, and one component of time is the accumulation of information."

A social planner who is interested in conserving the scarce biological resources in his or her country receives this information sequentially over time and in packets. This planner has a strictly monotonic and one-to-one utility function defined over these information packets. Because these packets provide information about the consequences of development (habitat conversion) and the existing stock of biodiversity, the resultant utility to the social planner is also about these two things. Now, a policy that involves waiting indefinitely and never stopping the natural habitat conversion process is a policy that results in the complete destruction of the existing stock of biodiversity. In most practical instances, such a policy will be inadmissible. Consequently, we account for this by imposing a constraint on the social planner's optimization problem. This constraint says that the social planner would like to stop the habitat conversion process by time $T=1 .^{6}$ This means that if the planner fails to stop the habitat conversion process by time $T=1$, then his or her utility is zero.

Our social planner receives information packets about the consequences of habitat conversion over time. These packets $P_{1}, P_{2}, P_{3}, \ldots$ are received in accordance with a Poisson process ${ }^{7}$ with a fixed rate $\lambda=1$. The packets themselves are independent random variables that are uniformly distributed on the interval $(0,1]$. The receipt of a packet generates a certain level of utility by means of the social planner's utility function. In other words, this utility function maps information about the effects of stopping conversion to utility from stopping conversion. Moreover, because the information packets are uniformly distributed on $(0,1]$ and because the utility function is strictly monotonic and one-to-one, the utility levels $U_{1}, U_{2}, U_{3}, \ldots$ themselves are also uniformly distributed random variables on the interval $(0,1]$. Upon receipt of an information packet and the corresponding utility, the social planner decides whether to stop the conversion of natural habitat or to permit conversion and wait for additional information. In this paper, stopping the natural habitat conversion process should be viewed as an action that results in the creation of a protected area. Examples of such protected areas include Corbett National Park in India and the Pico da Neblina National Park in Brazil. The reader will note that in essence, it is information that is the driving force behind the social planner's decision about when to stop the habitat conversion process.

In order to accomplish his or her objective of stopping the conversion of natural habitat by time $T=1$, our social planner will need to use a policy. In this paper we shall consider two types of policies. The first policy is the autonomous one and this policy is of the following type: The social planner decides on some threshold level of utility $\hat{U}$

\footnotetext{
6 The specific value of $T$ is not terribly important. Given our earlier assumption about the choice of units and the interval $(0,1]$, the value $T=1$ makes our subsequent computations tractable. However, the reader should note that by an appropriate choice of units and interval, an analysis of the sort conducted in this paper can be carried out for any finite $T$. Also, observe that by employing this constraint, we are ensuring that our social planner will stop the habitat conversion process. The germane question is: "When?"

7 For lucid discussions of the Poisson process, see Ross (1996, pp. 59-97) and Taylor and Karlin (1998, pp. 267-331).
} 
that is independent of time. With this policy, our social planner will stop the stochastic habitat conversion process (create a protected area) upon receipt of the first information packet whose utility exceeds $\hat{U}$. For example, using this autonomous policy, if our social planner creates a protected area upon receipt of the fourth information packet, then it must be true that $U_{1} \leq \hat{U}, U_{2} \leq \hat{U}, U_{3} \leq \hat{U}$, and $U_{4}>\hat{U}$. The second policy is the nonautonomous policy and in this case the threshold level of utility is a function of time $t$. In other words, instead of working with a constant $\hat{U}$, our social planner will now work with a time dependent threshold $\hat{U}(t)$, where $\hat{U}(t)=(1-t) /(3-t)$.

There are five reasons for working with the time dependent threshold function $\hat{U}(t)=$ $(1-t) /(3-t)$. First, the use of this function enables us to capture the dependence of the threshold on time in a simple manner and it permits us to obtain an analytical solution to the problem described in Section 3.2 below. Second, even though the specified function is relatively straightforward, the use of this function permits us to model and study the nonlinear dependence of time on the threshold. Third, the use of the above function lets us compare the merits of autonomous and nonautonomous policies directly. Fourth, the above specified function is consistent with our intuition that the social planner's decision making threshold ought to decline over time. Finally, there is a precedent (see Batabyal (2001)) in the economics literature for studying this kind of threshold function. We now proceed to our analysis of the autonomous policy.

\section{ALTERNATE POLICIES AND THEIR EFFECTS}

\subsection{The autonomous policy}

Our objective in this section is to compute the expected utility of our social planner when (s)he uses an autonomous policy with utility threshold $\hat{U}$. To this end, let us first compute the probability of creating a protected area by time $T=1$ when this policy is used. Because the utility stochastic process deriving from the stochastic information packet process is a Poisson process with rate $\lambda=1$, we can tell that the probability we seek is

$$
\text { Prob }\{\text { creating protected area by } T=1\}=1-\exp \{-(1-\hat{U})\} \text {. }
$$

Our next task is to ascertain the expected utility of the information packet that results in our social planner agreeing to create a protected area by time $T=1$. Now, recall that these utilities are uniformly distributed on the interval $(0,1]$. Hence, given that our social planner creates a protected area by time $T=1$, the expected utility of the information packet that results in the stopping of the natural habitat conversion process is $(1+\hat{U}) / 2$. We can now ascertain our social planner's expected utility $E U_{A}$ from the creation of a protected area with an autonomous policy. This is given by multiplying $(1+\hat{U}) / 2$ by the probability on the right hand side (RHS) of equation (1). We get

$$
E U_{A}=\left[\frac{1+\hat{U}}{2}\right][1-\exp \{-(1-\hat{U})\}]
$$


Equation (2) tells us that when an autonomous policy is used, the expected utility to the social planner from the creation of a protected area is the product of two terms in square brackets. Both these terms in the square brackets contain the utility threshold $\hat{U}$. Note that equation (2) is also our social planner's objective function. Consequently, with this information in mind, we can now ask the following question: What value of the utility threshold $\hat{U}$ should our social planner pick to maximize his or her expected utility from the creation of a protected area? This question can be answered by letting our social planner solve

$$
\max _{\hat{U}}\left[\left[\frac{1+\hat{U}}{2}\right][1-\exp \{-(1-\hat{U})\}]\right] .
$$

This is a straightforward but laborious maximization problem. Simplifying the maximand in equation (3), we can rewrite it as $\max _{\hat{U}}[1 / 2-(1 / 2) \exp \{-(1-\hat{U})\}+\hat{U} / 2-$ $(\hat{U} / 2) \exp \{-(1-\hat{U})\}]$. The first order necessary condition to this expected utility maximization problem is $\exp \{-(1-\hat{U})\}+(\hat{U} / 2) \exp \{-(1-\hat{U})\}-1 / 2=0$. It is possible to rewrite this first order necessary condition. This gives us $\log _{e}(2+\hat{U})-(1-\hat{U})=0$. Finally, this last equation can be expressed as

$$
\hat{U}+\log _{e}(2+\hat{U})=1 .
$$

Because $\hat{U} \in(0,1]$, it is easy to see that the solution to equation (4) is $\hat{U}^{*}=0.2079$. This means that if our social planner sets the value of the utility threshold $\hat{U}^{*}=0.2079$, then (s)he will have maximized his or her expected utility from stopping the natural habitat conversion process.

What is the maximized value of our social planner's expected utility? This query can be answered by substituting $\hat{U}^{*}=0.2079$ into equation (2). This tells us that our social planner's maximized expected utility from the creation of a protected area is

$$
E U_{A}^{*}=\left[\frac{1+\hat{U}^{*}}{2}\right]\left[1-\exp \left\{-\left(1-\hat{U}^{*}\right)\right\}\right]=0.330425 .
$$

Equation (5) tells us that the expected utility to our social planner when (s)he uses the optimal autonomous policy is 0.330425 . In other words, this is the highest level of expected utility that our social planner can hope to attain with an autonomous policy. This state of affairs naturally leads to the following question: Can our social planner do better by using a nonautonomous policy? We now proceed to answer this question.

\subsection{The nonautonomous policy}

Our goal now is to calculate the social planner's expected utility from the creation of a protected area when (s)he uses the nonautonomous policy $\hat{U}(t)=(1-t) /(3-$ $t$ ). Continuing in the same manner as in the previous section, let us first ascertain the probability of stopping the habitat conversion process by time $T=1$ when the above nonautonomous policy is used. Because the policy being used now is time dependent, the probability that we're interested in can be determined by computing the likelihood of creating a protected area in a small time interval $[t, t+d t]$. To compute this likelihood, we shall use two facts and the cumulative distribution function (cdf) for an exponentially 
distributed random variable (see Ross (1996, p. 35)). The two facts are (i) the relevant utility stochastic process is a Poisson process with rate $\lambda=1$ and (ii) the interarrival times for this Poisson process are exponentially distributed random variables with mean equal to $1 / \lambda=1 / 1=1$ (see Ross (1996, p. 64) and Taylor and Karlin (1998, p. 292) for additional details). Using these two facts and the cdf for an exponentially distributed random variable, the likelihood we seek is

$$
\begin{aligned}
& \text { Prob }\{\text { creating protected area within }[t, t+d t]\} \\
& \qquad=\exp \left\{-\int_{0}^{t}(1-\hat{U}(s)) d s\right\}\{1-\hat{U}(t)\} d t .
\end{aligned}
$$

Comparing equations (1) and (6), we see that the time dependence of the nonautonomous policy complicates the computation of the probability of creating a protected area. We now need to calculate the expected utility of the information packet that results in our social planner stopping the habitat conversion process by time $T=1$. Once again, continuing as in the previous section, we obtain a similar expression for this expected utility. Consequently, we can now determine our social planner's expected utility $E U_{N}$ from the creation of a protected area with a nonautonomous policy. This is given by multiplying $(1+\hat{U}(t)) / 2$ by the probability on the RHS of equation (6) and then integrating the resulting expression between 0 and 1 . Mathematically, we have

$$
E U_{N}=\int_{0}^{1}\left[\frac{1+\hat{U}(t)}{2}\right] \exp \left\{-\int_{0}^{t}(1-\hat{U}(s)) d s\right\}\{1-\hat{U}(t)\} d t
$$

Equation (7) tells us that when a nonautonomous policy is used, the expected utility from the creation of a protected area is the product of two terms. As in the previous section, both these terms contain the utility threshold $\hat{U}(\cdot)$. Also, observe that equation (7) is our social planner's objective function. However, because of the time dependent nature of our social planner's nonautonomous policy, we cannot now calculate an optimal $\hat{U}^{*}$ as we did in the previous section.

This notwithstanding, we can still ask: What is the maximized value of our social planner's expected utility when (s)he uses a nonautonomous policy? To answer this question, we will need to complete the integrations in equation (7). Let us first complete the integration in the expression for the probability of creating a protected area in the interval $[t, t+d t]$, i.e., in the second term on the RHS of equation (7). Integrating, we get

$$
\exp \left\{-\int_{0}^{t}(1-\hat{U}(s)) d s\right\}\{1-\hat{U}(t)\} d t=\frac{1}{9}\left(\frac{2}{3-t}\right) \exp \left\{2 \log _{e}(3-t)\right\} d t
$$

Using equation (8), we can greatly simplify the objective function delineated by equation (7). This simplification yields

$$
E U_{N}=\frac{2}{9} \int_{0}^{1}(2-t) d t
$$


Now completing the integration in equation (9), we get

$$
E U_{N}^{*}=\frac{2}{9} \int_{0}^{1}(2-t) d t=0.333333
$$

Equation (10) tells us that the expected utility of our social planner when (s)he uses a nonautonomous policy is 0.333333 . In other words, this is the highest level of expected utility that our social planner can hope to achieve with the nonautonomous policy $\hat{U}(t)=(1-t) /(3-t)$. We now compare and contrast the properties of autonomous and nonautonomous policies and then we discuss the magnitude of the premium arising from the maintenance of temporal flexibility in decision making.

\section{AUTONOMOUS VERSUS NONAUTONOMOUS POLICIES}

In principle, for reasons given in Section 1, we expect autonomous and nonautonomous policies to yield very different payoffs to our social planner. Our analysis thus far allows us to shed light on this and associated issues. In particular, we can use Table 1 to compare and contrast the properties of these two distinct policies. Reading horizontally, the second row of Table 1 reveals the basic difference in the two policies. In the autonomous case, the optimal value of the utility threshold $\hat{U}$ is fixed at 0.2079 and this value does not change with the passage of time. In contrast, when our social planner uses a nonautonomous policy, the utility threshold is continually a function of time and hence its optimal value varies with the passage of time.

The third row of Table 1 gives us exact values of the expected utility from the creation of a protected area when these two policies are used by our social planner. Relative to an autonomous policy, a nonautonomous policy allows a social planner to be flexible in the face of changing conditions. In particular, the reader should note the nexus between this flexibility and the constraint describing our social planner s desire to stop the conversion of natural habitat by a certain time. To see this connection plainly, consider the following example: We have chosen units so that the time by which our social planner would like to create a protected area is $T=1$. For the purpose of this example, let us measure time in years and suppose that the time constraint is $T=40$ years. Then, it is reasonable to say that the optimal value of $\hat{U}$ for our social planner at $T=10$ years will

Table 1. A comparison of autonomous and nonautonomous conservation policies.

\begin{tabular}{ccc}
\hline Criterion of interest & $\begin{array}{c}\text { Autonomous conservation } \\
\text { policy }\end{array}$ & $\begin{array}{c}\text { Nonautonomous } \\
\text { conservation policy }\end{array}$ \\
\hline $\begin{array}{l}\text { Optimal value of utility threshold } \\
\text { Maximal expected utility from } \\
\text { Creation of protected area }\end{array}$ & $\hat{U}^{*}=0.2079$ & $\hat{U}(t)=\frac{1-t}{3-t}$ \\
$\begin{array}{c}\text { Premium from the maintenance of } \\
\text { temporal flexibility }\end{array}$ & $E U_{A}^{*}=0.330425$ & $E U_{N}^{*}=0.333333$ \\
\hline
\end{tabular}


most likely be different from the optimal value of $\hat{U}$ at $T=35$ years. Now, in contrast with an autonomous policy, the use of a nonautonomous policy allows our social planner to alter the value of $\hat{U}$ over time and hence, in general, this policy is more flexible and therefore more desirable. The third row of Table 1 shows that this reasoning is right because $E U_{N}^{*}=0.333333>0.330425=E U_{A}^{*}$.

How much more desirable is the nonautonomous policy? The simple answer is: Not much more. As shown in the fourth row of Table 1, the premium associated with the maintenance of temporal flexibility in decision making is positive but only 0.002908 . Consequently, in the theoretical framework of this paper, our social planner does almost as well by using an autonomous policy.

To summarize, we obtain the following five insights from our analysis thus far: First, the time dependence of the threshold in Section 3.2 permits our social planner to be flexible. Second, when making habitat conversion stoppage decisions (biodiversity conservation decisions) over time and under uncertainty, it pays to be flexible. Third, although the use of more complex nonautonomous policies will most likely increase the magnitude of the flexibility premium, these more complex nonautonomous policies often do not admit closed-form solutions. Fourth, we can view the decision to create a protected area as a decision to invest in biodiversity. Finally, if we view the decision to create a protected area as a decision to invest in biodiversity, then, the result depicted in the second row of Table 1 - that it is optimal to wait a while before investing - is consistent with the "value of waiting to invest" result in the investment under uncertainty literature (see Dixit and Pindyck (1994).

\section{CONCLUSIONS}

In this paper we provided a theoretical analysis of the effects of alternate policies on the decision to stop the conversion of natural habitat in a dynamic and stochastic framework. To the best of our knowledge, this is the first paper to provide a comparative analysis of the properties of autonomous and nonautonomous policies in the context of the conservation of biodiversity. After pointing out the basic difference between autonomous and nonautonomous policies, our analysis showed that nonautonomous policies are generally more desirable than autonomous policies because the expected utility from the creation of a protected area when a nonautonomous policy is used exceeds the expected utility from the creation of a protected area with an autonomous policy. In other words, there is a positive flexibility premium associated with the use of a nonautonomous policy.

The analysis in this paper can be extended in a number of directions. In what follows, we suggest two possible extensions. First, note that the social planner's optimal policy is of an "all or nothing" type. In other words, the social planner either stops all conversion or permits all conversion to continue. Following recent developments in the literature on the development of land over time and under uncertainty (see Miller and Lad (1984) and Batabyal (1999)), it would be useful to examine the social planner's decision problem when partial stopping is a possibility. 
Second, the time dependent decision rule that we've studied in this paper involves altering the value of the utility threshold. However, the form of the policy itself does not change. Accordingly, it would be useful to compare and contrast the properties of the nonautonomous policy of this paper with a different policy that involves the temporal modification of the form of the policy. An analysis of these aspects of the problem will allow richer analyses of the nexuses between alternate policies and the decision to conserve biodiversity over time and under uncertainty.

\section{REFERENCES}

Aldhous, P. 1993. Tropical Deforestation: Not Just a Problem in Amazonia, Science, 259, 1390.

Barbier, E. B. and Rauscher, M. 1995. Policies to Control Tropical Deforestation: Trade Intervention versus Transfers, in Perrings, C., Maler, K. G., Folke, C., Holling, C. S. and Jansson, B. O. (Eds.), Biodiversity Loss. Cambridge University Press, Cambridge, UK.

Barrett, S. 1995. On Biodiversity Conservation, in Perrings, C., Maler, K. G., Folke, C., Holling, C. S. and Jansson, B. O. (Eds.), Biodiversity Loss. Cambridge University Press, Cambridge, UK.

Batabyal, A. A. 1998. An Optimal Stopping Approach to the Conservation of Biodiversity, Ecological Modelling, 105, 293-298.

Batabyal, A. A. 1999. On Some Aspects of Land Development When the Decision to Develop is Divisible, Resources Policy, 25, 173-177.

Batabyal, A. A. 2000. Habitat Conversion, Information Acquisition, and the Conservation of Biodiversity, Journal of Environmental Management, 59, 195-203.

Batabyal, A. A. 2001. Alternate Decision Rules, the Flexibility Premium, and Land Development Over Time and Under Uncertainty, Forthcoming, Stochastic Environmental Research and Risk Assessment.

Dixit, A. K. and Pindyck, R. S. 1994. Investment Under Uncertainty. Princeton University Press, Princeton, New Jersey.

Ehrlich, P. R. 1994. Energy Use and Biodiversity Loss, Philosophical Transactions of the Royal Society, London, B, 344, 99-104.

Gadgil, M. 1995. Prudence and Profligacy: A Human Ecological Perspective, in Swanson, T. M. (Ed.), The Economics and Ecology of Biodiversity Decline. Cambridge University Press, Cambridge, UK.

Hartwick, J. M. 1995. Decline in Biodiversity and Risk-Adjusted Net National Product, in Swanson, T. M. (Ed.), The Economics and Ecology of Biodiversity Decline. Cambridge University Press, Cambridge, UK.

Krautkraemer, J. A. 1995. Incentives, Development, and Population: A Growth-Theoretic Perspective, in Swanson, T. M. (Ed.), The Economics and Ecology of Biodiversity Decline. Cambridge University Press, Cambridge, UK.

Miller, J. R. and Lad, F. 1984. Flexibility, Learning, and Irreversibility in Environmental Decisions: A Bayesian Approach, Journal of Environmental Economics and Management, 11, 161-172.

Myers, N. 1992. The Primary Source. W. W. Norton, New York, New York.

Perrings, C., Maler, K. G., Folke, C., Holling, C. S. and Jansson, B. O. (Eds.). 1995a. Biodiversity Loss. Cambridge University Press, Cambridge, UK.

Perrings, C., Maler, K. G., Folke, C., Holling, C. S. and Jansson, B. O. 1995b. Introduction: Framing the Problem of Biodiversity Loss, in Perrings, C., Maler, K. G., Folke, C., Holling, C. S. and Jansson, B. O. (Eds.), Biodiversity Loss. Cambridge University Press, Cambridge, UK.

Polasky, S. and Solow, A. R. 1995. On the Value of a Collection of Species, Journal of Environmental Economics and Management, 29, 298-303.

Ross, S. M. 1983. Introduction to Stochastic Dynamic Programming. Academic Press, San Diego, California. Ross, S. M. 1996. Stochastic Processes, 2nd edition. John Wiley and Sons, New York, New York.

Simpson, R. D., Sedjo, R. A. and Reid, J. W. 1996. Valuing Biodiversity for Use in Pharmaceutical Research, Journal of Political Economy, 104, 163-185. 
Smith, F. D. M., Daily, G. C. and Ehrlich, P. R. 1995. Human Population Dynamics and Biodiversity Loss, in Swanson, T. M. (Ed.), The Economics and Ecology of Biodiversity Decline. Cambridge University Press, Cambridge, UK.

Solow, A. R., Polasky, S. and Broadus, J. 1993. On the Measurement of Biological Diversity, Journal of Environmental Economics and Management, 24, 60-68.

Solow, A. R. and Polasky, S. 1994. Measuring Biological Diversity, Environmental and Ecological Statistics, $1,95-103$.

Southgate, D. 1995. Economic Progress and Habitat Conservation in Latin America, in Swanson, T. M. (Ed.), The Economics and Ecology of Biodiversity Decline. Cambridge University Press, Cambridge, UK.

Swanson, T. M. (Ed.). 1995a. The Economics and Ecology of Biodiversity Decline. Cambridge University Press, Cambridge, UK.

Swanson, T. M. 1995b. The International Regulation of Biodiversity Decline: Optimal Policy and Evolutionary Product, in Perrings, C., Maler, K. G., Folke, C., Holling, C. S. and Jansson, B. O. (Eds.), Biodiversity Loss. Cambridge University Press, Cambridge, UK.

Taylor, H. M. and Karlin, S. 1998. An Introduction to Stochastic Modeling, 3rd edition. Academic Press, San Diego, California.

Terborgh, J. 1992. Tropical Deforestation. Carolina Biological Supply, Burlington, North Carolina.

Terborgh, J. and van Schaik, C. 1997. Minimizing Species Loss: The Imperative of Protection, in Kramer, R., van Schaik, C. and Johnson, J. (Eds.), Last Stand. Oxford University Press, New York, New York.

Weitzman, M. L. 1992. On Diversity, Quarterly Journal of Economics, 107, 363-406.

Weitzman, M. L. 1993. What to Preserve: An Application of Diversity Theory to Crane Conservation, Quarterly Journal of Economics, 108, 157-184.

Weitzman, M. L. 1995. Diversity Functions, in Perrings, C., Maler, K. G., Folke, C., Holling, C. S. and Jansson, B. O. (Eds.), Biodiversity Loss. Cambridge University Press, Cambridge, UK.

Whitmore, T. C. and Sayer, J. A. 1992. Tropical Deforestation and Species Extinction. Chapman and Hall, London, UK.

Wilson, E. O. 1992. The Diversity of Life. Harvard University Press, Cambridge, Massachusetts. 